\title{
RESULTS FROM CLINICAL AND RADIOLOGICAL FOLLOW-UP, AFTER SURGICAL TREATMENT OF CHONDROBLASTOMA
}

Valter Penna', Eduardo Areas Toller ${ }^{2}$, Adriano Jander Ferreira ${ }^{3}$, Dante Palloni Costa Dias ${ }^{3}$

\section{ABSTRACT}

Objectives: To evaluate the long-term clinical and radiological results from patients who underwent surgical treatment of chondroblastoma, between 2003 and 2009, by the same surgical team, using the same operative technique. Methods: A retrospective study was conducted on 12 patients with histological diagnoses of chondroblastoma, who were attended between 2003 and 2009 at the Pius XII Foundation (Barretos Cancer Hospital, Barretos, State of São Paulo). These patients underwent surgical treatment with intralesional resection of the tumor, adjuvant electrocauterization and replacement with methyl methacrylate (11 cases) or an autologous graft from the iliac crest (one case). The preoperative evaluation included physical examination, plain radiographs of the site, magnetic resonance imaging, computed axial tomography and bone scintigraphy. The patients were assessed clinically and radiologically according to a predefined protocol, with a series of plain radiographs, and a functional assessment in accordance with the Enneking functional score. Results: The average age at the time of diagnosis was 14 years and 4 months. The most frequent location affected was the distal femoral epiphysis (75\%), followed by the proximal tibial epiphysis $(16.6 \%)$ and the calcaneus $(8.4 \%)$. There was higher prevalence among the female patients than among the male patients (3:1). In three cases, preoperative biopsy was necessary. During the follow-up, there was no evidence of local tumor recurrence, and all the patients presented an excellent functional result from the surgical technique used, with Enneking scores ranging from 20 to 30. Conclusion: Surgical treatment of chondroblastoma, using intralesional resection, adjuvant electrocauterization and replacement with methyl methacrylate or bone graft produced good results.

Keywords - Chondroblastoma; Neoplasms; Retrospective Studies

\section{INTRODUCTION}

Bone chondroblastoma is an infrequent benign lesion with a potential for aggressiveness through local growth. It corresponds to $1-2 \%$ of cases of primary neoplasia and $9 \%$ of all benign bone tu$\operatorname{mors}^{(1,2)}$.

Neoplastic transformation of cells from the epiphysis or from secondary ossification centers is considered to be the histogenetic origin of these lesions. Like giant cell bone tumors, chondroblastomas have a predilection for the epiphysis and apophysis of long tubular bones. They are much less frequent in the small bones of the hand or foot, or in the pelvis. Their peak incidence is in the second decade of life, in contrast with giant cell tumors, which only exceptionally affect children and adolescents ${ }^{(3,4)}$.

Malignant transformation of chondroblastomas has been described ${ }^{(5-9)}$.

1 - Head of the Orthopedic Oncology Service, Barretos Cancer Hospital, Pius XII Foundation, Barretos, SP, Brazil.

2 - Titular Physician in the Orthopedic Oncology Service, Barretos Cancer Hospital, Pius XII Foundation, Barretos, SP, Brazil.

3 - Resident Physician in the Orthopedic Oncology Service, Barretos Cancer Hospital, Pius XII Foundation, Barretos, SP, Brazil.

Work performed at Barretos Cancer Hospital, Pius XII Foundation, Barretos, SP, Brazil

Correspondence: Departamento de Oncologia Ortopédica, Rua Antenor Duarte Vilela 1331, Bairro Dr. Paulo Prata, $14784-400$ Barretos, SP.

E-mail: valter penna@terra.com.br

Work received for publication: December 1, 2010; accepted for publication: February 16, 2011. 
The differential diagnosis for chondroblastomas includes giant cell tumors, chondromyxoid fibroma, aneurysmatic bone cysts and clear cell chondrosarcoma $^{(10)}$. The radiological appearance consists of an eccentric lesion on long bones, sometimes totally radiolucent and sometimes trabeculated, with areas of calcification. The margins are almost always well delimited and clear, with sclerotic rims. The growth plate is still open in the great majority of cases ${ }^{(10)}$.

The treatment of choice is surgical, which requires special care and may be complicated because of the proximity of the joint and the close relationship with the growth plate. The postsurgical recurrence rate is between 8 and $35 \%$ and is also influenced by the biological activity of the lesion ${ }^{(4,11-14)}$.

In very rare cases, metastases can occur, mainly in the lungs. In extremely rare cases, these metastases may cause death ${ }^{(15)}$.

The aim of this study was to gather together the long-term results from patients who underwent surgical treatment for chondroblastoma, between 2003 and 2009, by the same surgical team and using the same operative technique.

\section{METHODS}

In this study, 12 patients with histological diagnoses of chondroblastoma who were attended at Barretos Cancer Hospital, Pius XII Foundation, Barretos, SP, between 2003 and 2009, were evaluated.

The patients were studied retrospectively. The preoperative analysis consisted of a physical examination, simple radiography (Figure 1), bone scintigraphy and local computed tomography or magnetic resonance imaging (Figure 2). Three patients underwent preoperative biopsy.

The biological activity was indicated by the meaning of the clinical and radiological stage of the benign tumors, in accordance with the Enneking classification $^{(15)}$.

The patients underwent surgical treatment of the chondroblastoma, which involved intralesional resection of the tumor, curettage, electrocauterization and volume replacement (Figure 3). In 11 cases, the lesions were replaced by methyl methacrylate and in one case, by an autologous bone graft from the iliac crest.

Simple radiographs were obtained during the immediate postoperative period (Figure 4) and every six months thereafter over the first two years. After this time, the radiological control became yearly. In cases of irregularities seen on the radiographs, magnetic resonance imaging was requested to complement the diagnosis.

The functional assessment on the patients after the operation was based on the MSTS Enneking score ${ }^{(16)}$.

The following data on the patients is presented in Table 1: location, age, sex, length of time with symptoms, Enneking classification, growth plate open or closed, surgical treatment, Enneking functional assessment and results later on (Table 1).

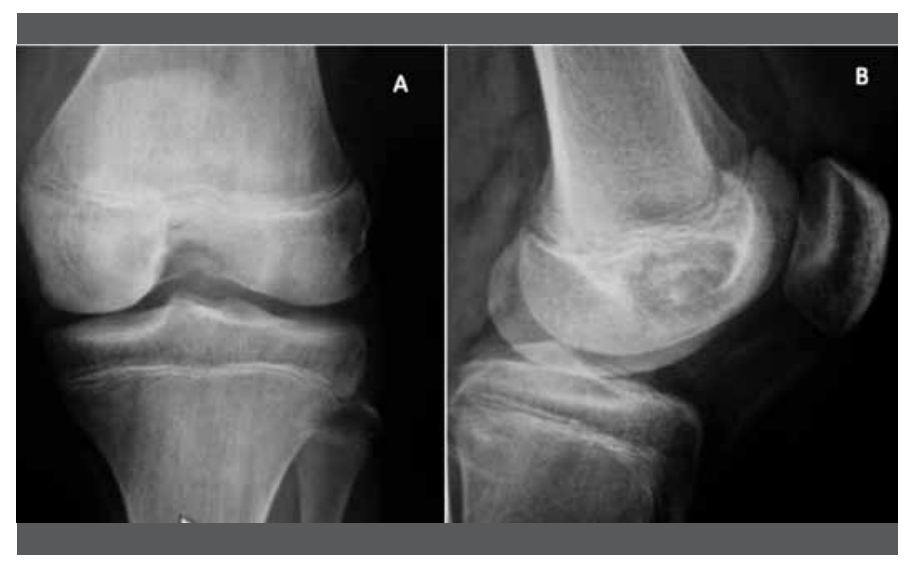

Figure 1 - Radiograph of an adolescent's knee. (A) AP view demonstrating epiphyseal lytic lesion in the femoral intercondyle, with well-defined limits; (B) Lateral view demonstrating epiphyseal lytic lesion, with well defined appearance and sclerotic rim.

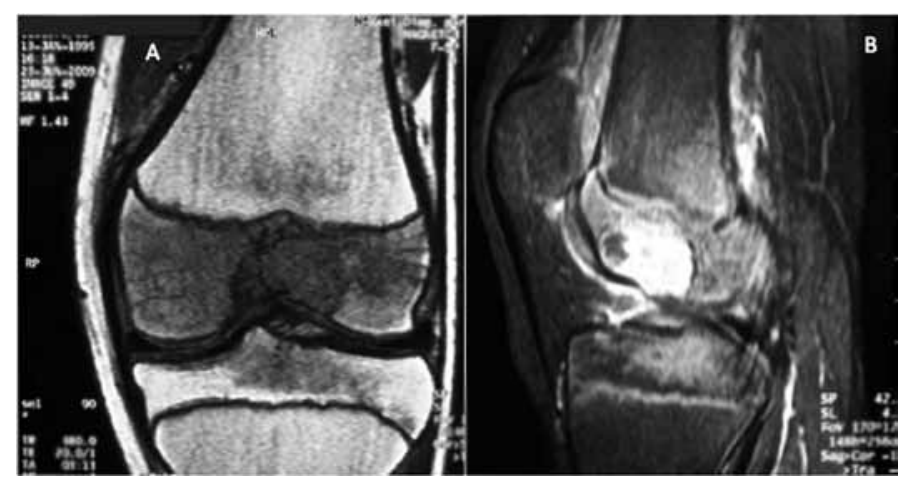

Figure 2 - MRI on an adolescent's knee. (A) Coronal section with T1 weighting, demonstrating a lesion with hyposignal in the epiphyseal region of the femoral intercondyle; (B) Sagittal section with T2 weighting, demonstrating a lesion with hypersignal in the epiphyseal region. 


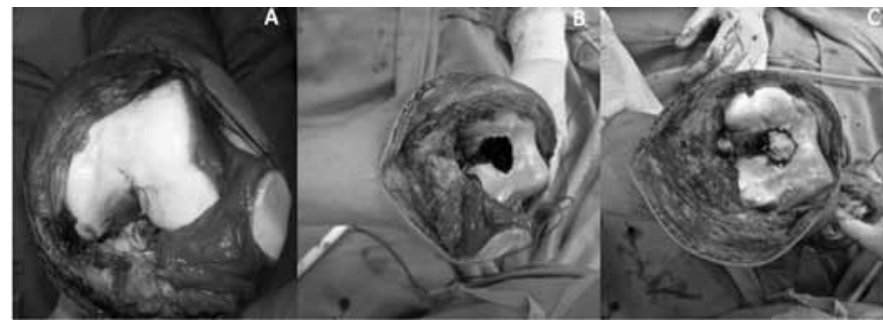

Figure 3 - During the operation on a chondroblastoma of the distal femur. (A) Intercondylar neoplasia; (B) Appearance after curettage and electrocauterization; C) Appearance after cementation with methyl methacrylate.

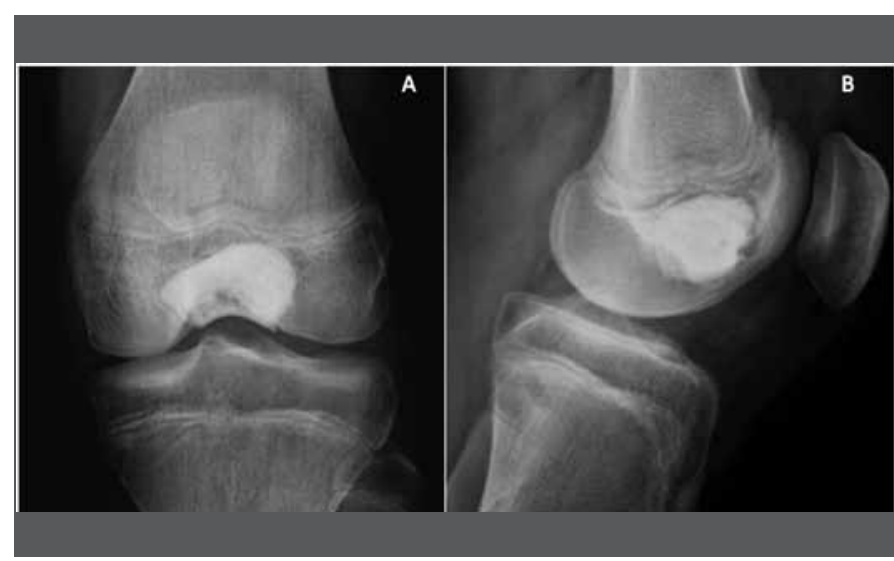

Figure 4 - Postoperative radiograph on an adolescent's knee. (A) AP view demonstrating presence of methyl methacrylate in the region of the femoral intercondyle; (B) Lateral view demonstrating presence of methyl methacrylate in the epiphyseal region.

\section{RESULTS}

All the patients included in the study were followed up for a minimum of one year. Their mean age was 14 years and 4 months (range: 12 years and 2 months to 17 years and 2 months). The incidence among males, in relation to females, was $3: 1$, and $100 \%$ of the lesions were diagnosed during the second decade of life. The most frequent location was the epiphysis of the distal femur (75\%), followed by the epiphysis of the proximal tibia $(16.6 \%)$ and one case on the calcaneus $(8.4 \%)$.

Regarding the clinical and radiological stages, 75\% of the cases were in stage B2 (active benign) and 25\% were in stage B3 (aggressive benign).

Bone scintigraphy was performed on all patients and showed a monostotic lesion, with low uptake of the radiopharmaceutical in the bone involved. None of the patients presented local recurrence with the surgical technique used, and the volume replacement was achieved using methyl methacrylate or an autologous bone graft from the iliac crest.

During the follow-up period, none of the skeletally immature cases presented premature closure of the growth plate or angular deviation of the affected limb.

In $25 \%$ of the cases, there was an association with fibrous cortical bone defects, shown by the simple radiographs obtained during the preoperative assessment.

In all the cases involved in this study, the evaluation using the Enneking functional score attained between 20 and 30 points (excellent) (Table 1).

\section{DISCUSSION}

Chondroblastomas are rare benign tumors and there are only a few published retrospective studies in the literature. The present study demonstrates the experience of a single service during the clinical and radiological follow-up after surgical treatment of chondroblastoma.

Table 1 - Data on the patients involved in this study.

\begin{tabular}{c|c|c|c|c|c|c|c}
\hline Patient & Site & Age/sex & Symptoms & Activity & Treatment & MSTS-Enneking & Postoperative \\
\hline 1 & Calcaneus & $13 \mathrm{y} / \mathrm{F}$ & Pain/edema & B3 $^{\star *}$ & Curettage/graft & Excellent & Consolidation \\
\hline 2 & Distal femur & $17 \mathrm{y} / \mathrm{M}$ & Pain/edema & B2 & Curettage/cement & Excellent & No recurrence \\
\hline $3^{*}$ & Distal femur & $12 \mathrm{y} / \mathrm{M}$ & Pain/edema & B2 & Curettage/cement & Excellent & No recurrence \\
\hline 4 & Distal femur & $16 \mathrm{y} / \mathrm{M}$ & Pain & B2 & Curettage/cement & Excellent & No recurrence \\
\hline 5 & Distal femur & $13 \mathrm{y} / \mathrm{M}$ & Pain & B2 & Curettage/cement & Excellent & No recurrence \\
\hline $6^{*}$ & Distal femur & $14 \mathrm{y} / \mathrm{M}$ & Pain & B2 & Curettage/cement & Excellent & No recurrence \\
\hline 7 & Distal femur & $16 \mathrm{y} / \mathrm{M}$ & Pain & B2 & Curettage/cement & Excellent & No recurrence \\
\hline 8 & Distal femur & $13 \mathrm{y} / \mathrm{F}$ & Pain & B3 ${ }^{* *}$ & Curettage/cement & Excellent & No recurrence \\
\hline 9 & Proximal tibia & $12 \mathrm{y} / \mathrm{F}$ & Pain & B2 & Curettage/cement & Excellent & No recurrence \\
\hline 10 & Proximal tibia & $16 \mathrm{y} / \mathrm{M}$ & Pain & B2 & Curettage/cement & Excellent & No recurrence \\
\hline $11^{*}$ & Distal femur & $14 \mathrm{y} / \mathrm{M}$ & Pain & B3 & Curettage/cement & Excellent & No recurrence \\
\hline 12 & Distal femur & $12 \mathrm{y} / \mathrm{M}$ & Pain & B2 & Curettage/cement & Excellent & No recurrence \\
\hline
\end{tabular}

* Patients with an association between chondroblastoma and fibrous cortical bone defect.

** Patients who underwent prior biopsy. 
In all of our cases, the age at which the tumor affected the patient was in the second decade of life, and there was a predilection for occurrences among males. These findings were similar to the data in the literature ${ }^{(17-19)}$.

Chondroblastomas can occur in any bone with endochondral ossification ${ }^{(11)}$. Most studies have indicated that the most frequent sites are the proximal epiphysis of the humerus, distal femur and proximal tibia ${ }^{(7,18-20)}$. We found that the epiphysis of the distal femur was the most frequent site, followed by the proximal tibia and a single case on the calcaneus.

The most frequent symptom presented by the patients was joint pain, followed by joint effusion. The mean time that elapsed between the start of symptoms and the diagnosis was around nine months.

The typical location and the radiological appearance of the biological activity of the lesion are important in determining the differential diagnoses of the lesion $^{(1)}$. The cystic lesions, which were well defined and presented sclerotic rims, were subjected to resection without previous biopsies. The lesions with a radiological appearance of biological activity outside of the patterns described above were subjected to prior biopsy (three cases), given that malignant tumors such as low-grade osteosarcoma and chondrosarcoma have been described at these sites, albeit rarely ${ }^{(11)}$.

The local recurrence rate reported in the literature is between 8 and $35 \%$. In our cases, using intralesional resection followed by adjuvant treatment with

\section{REFERENCES}

1. Erlemann R. [Radiological diagnosis of bone tumors. 1]. Radiologe. 2001t;41(10):930-43.

2. Schaser KD, Bail HJ, Haas NP, Melcher I. [Treatment concepts of benign bone tumors and tumor-like bone lesions]. Chirurg. 2002;73(12):1181-90.

3. Atalar H, Basarir K, Yildiz Y, Erekul S, Saglik Y. Management of chondroblastoma: retrospective review of 28 patients. J Orthop Sci. 2007;12(4):334-40

4. Ramappa AJ, Lee FY, Tang P, Carlson JR, Gebhardt MC, Mankin HJ. Chondroblastoma of bone. J Bone Joint Surg Am. 2000;82(8):1140-5.

5. Lin PP, Thenappan A, Deavers MT, Lewis VO, Yasko AW. Treatment and prognosis of chondroblastoma. Clin Orthop Relat Res. 2005;438:103-9.

6. Masui F, Ushigome S, Kamitani K, Asanuma K, Fujii K. Chondroblastoma: a study of 11 cases. Eur J Surg Oncol. 2002;28(8):869-74.

7. Springfield DS, Capanna R, Gherlinzoni F, Picci P, Campanacci M. Chondroblastoma. A review of seventy cases. J Bone Joint Surg Am. 1985;67(5):748-55.

8. Suneja R, Grimer RJ, Belthur M, Jeys L, Carter SR, Tillman RM, et al.. Chondroblastoma of bone: long-term results and functional outcome after intralesional curettage. J Bone Joint Surg Br. 2005;87(7):974-8.

9. van der Geest IC, van Noort MP, Schreuder HW, Pruszczynski M, de Rooy JW, Veth RP. The cryosurgical treatment of chondroblastoma of bone: long-term oncologic and functional results. J Surg Oncol. 2007;96(3):230-4.

10. Fechner RE, Mills SE. Chondroblastoma. In Atlas of tumor pathology. Tumors of the bones and joints. 3rd series,. Washington: Armed Forces Institute of Pathology (AFIP) Washington: Armed Forces Institute of Pathology; 1993.

11. Bloem JL, Mulder JD. Chondroblastoma: a clinical and radiological study of 104 cases. Skeletal Radiol. 1985;14(1):1-9. electrocauterization and replacement with methyl methacrylate (11 cases) or autologous bone graft from the iliac crest (one case), we did not observe any clinical or radiological signs of local recurrence during the follow-up.

The frequency of growth disorders has been reported to be $7-50 \%{ }^{(15,21)}$. During our follow-up, we did not observe any growth disorders and/or angular deviations in the limbs.

The functional limitations inherent to surgical treatment are only taken into consideration in a few studies. Around $10 \%$ of such patients present limitations later on ${ }^{(22)}$. The later functional assessments on the patients who underwent the surgical method used in this study showed that the results were excellent in $100 \%$ of the cases, with functional scores ranging from 20 to 30 points.

In three cases, there was an association with epiphyseal lesions, with fibrous cortical bone defect, which culminated in a delay in diagnosing the cases.

\section{CONCLUSION}

Surgical treatment of chondroblastoma, with intralesional resection, adjuvant treatment using electrocauterization and replacement with methyl methacrylate or autologous bone graft from the iliac crest, is a safe method that produces good long-term functional results and presents a low rate of local recurrence.

We draw attention to the possibility of an association between chondroblastoma and fibrous cortical bone defect, which in some cases may lead to delayed diagnosis.

12. Garin IE, Wang EH. Chondroblastoma. J Orthop Surg (Hong Kong). 2008;16(1):84-7.

13. Hsu CC, Wang JW, Chen CE, Lin JW. Results of curettage and high-speed burring for chondroblastoma of the bone. Chang Gung Med J. 2003;26(10):761-7.

14. Schuppers HA, van der Eijken JW. Chondroblastoma during the growing age. J Pediatr Orthop B. 1998;7(4):293-7.

15. Enneking WF. A system of staging musculoskeletal neoplasms. Clin Orthop Relat Res. 1986;(204):9-24.

16. Enneking WF, Dunham W, Gebhardt MC, Malawar M, Pritchard DJ. A system for the functional evaluation of reconstructive procedures after surgical treatment of tumors of the musculoskeletal system. Clin Orthop Relat Res. 1993;(286):241-6.

17. Corsat JP, Tomeno B, Forest M, Vinh TS. [Benign chondroblastoma. A review of 30 cases]. Rev Chir Orthop Reparatrice Appar Mot. 1989;75(3):179-87.

18. de Silva MV, Reid R. Chondroblastoma: varied histologic appearance, potential diagnostic pitfalls, and clinicopathologic features associated with local recurrence. Ann Diagn Pathol. 2003;7(4):205-13.

19. Dahlin DC, Ivins JC. Benign chondroblastoma. A study of 125 cases. Cancer. 1972;30(2):401-13.

20. Rybak LD, Rosenthal DI, Wittig JC. Chondroblastoma: radiofrequency ablation-alternative to surgical resection in selected cases. Radiology. 2009;251(2):599604.

21. Caterini R, Manili M, Spinelli M, Santori FS, Ippolito E. Epiphyseal chondroblastoma of bone. Long-term effects on skeletal growth and articular function in 15 cases treated surgically. Arch Orthop Trauma Surg. 1992;111(6):327-32.

22. Lehner B, Witte $D$, Weiss $S$. Clinical and radiological long-term results after operative treatment of chondroblastoma. Arch Orthop Trauma Surg. 2011;131(1):45-52. 